\title{
La otra cara. Políticas públicas, inclusión laboral y jóvenes urbanos de sectores populares en un movimiento social
}

\author{
The Other Side. Public Policy, Including Labor and Youth \\ Popular Sectors Urban Social Movement
}

ANALÍA ELIZABETH OTERO

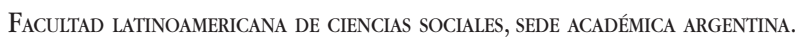

Programa DE INVESTIGACIONES SOBRE JUVENTUD

Artículo recibido: 9 abril 2014

Solicitud de revisión: 18 junio 2014

Artículo aceptado: 16 enero 2015

Resumen

El propósito del artículo es reflexionar sobre las políticas públicas implementadas desde el gobierno nacional hacia los movimientos sociales en el contexto argentino actual. El interés es debatir la influencia de los programas sociales -en particular el Programa de Ingreso Social con Trabajo (en adelante pat)- en la situación de los jóvenes de sectores urbanos populares. Lo haremos a partir de abordar la compleja relación entre los emprendimientos cooperativos, las políticas sociales y las estrategias de los jóvenes participantes en una experiencia territorial.

La base empírica resulta de una investigación cualitativa con militantes de un movimiento de trabajadores desocupados. Los hallazgos dan cuenta de múltiples tensiones; mientras que su adscripción a la acción colectiva promueve la autogestión y mediatiza el acceso a planes sociales, como componentes de la fuerza de trabajo en período activo y de formación, estos trabajadores siguen ubicados en posiciones marginales respecto al mercado de empleo.

Palabras clave: Política pública, jóvenes, sectores populares, movimientos sociales.

The other side. Public policy, including labor and youth popular sectors in urban social movement

Abstract

The purpose of this article is to reflect on the public policies implemented from the national government to the social movements in Argentina's current context. The interest is to discuss the influence of social programs, including Social Program Income through Work (hereafter pat) in the situation of young people from urban areas. We will address it 
from the complex relationship established among cooperative ventures, social policies and strategies of the young participants in a territorial experience.

The empirical basis is a qualitative research with a militant movement of unemployed workers. The findings realize multiple stresses; while its allegiance to collective action promotes self-management and mediates access to social programs as components of the active labor force and training period, which are located in marginal positions on the labor market.

Key Words: Public policy, youth, grassroots, social movements

\section{INTRODUCCIÓN}

En los noventa, en Argentina asistimos a una acentuación del conflicto social asociado a la consolidación de un régimen de acumulación iniciado a mediados de los 70 que implicó concentración de la riqueza, descapitalización del Estado, fuerte endeudamiento externo, y progresivo avance de la desindustrialización (Basualdo, 2000).

El inicio de la década del noventa significó la aplicación de medidas de corte neoliberal de ajuste estructural: la apertura del mercado, la privatización de las empresas públicas y la flexibilización de los contratos de trabajo. Como resultado, estas medidas contribuyeron al deterioro de las condiciones de vida de gran parte de la población, situación expresada a través de diversos indicadores, tales como los niveles inéditos de desempleo, la desigualdad distributiva y la pobreza extrema. La reestructuración del mercado de trabajo, visible en el aumento sostenido de la tasa de desocupación, precarización e informalidad, fueron procesos que impactaron fuertemente en nuestra sociedad.

Después del período de manifiesta crisis económica e institucional desde fines del siglo anterior, el contexto nacional comienza a dar signos de estabilidad política y un relativo crecimiento económico a partir del 2003. Desde entonces y hasta nuestros días, bajo gobiernos liderados por Néstor Kirchner y Cristina Fernández de Kirchner, se impulsaron una serie de medidas de políticas públicas que dan cuenta de una transformación respecto a la intervención pública en materia de empleo. Más específicamente, la estrategia del gobierno nacional apuntó a dar un nuevo salto en relación a la orientación de las políticas de empleo; para ello, puso en marcha el Plan Manos a la Obra y, luego, el Programa de Ingreso Social con Trabajo (ambos destinados a alentar o a promover la conformación de cooperativas de trabajo ligadas a la economía social). Se trataba de atender las problemá- 
ticas laborales a través de la generación de empleos vinculados a propuestas autogestivas en unidades productivas de trabajo colectivo.

Si bien estos programas no están diseñados exclusivamente para la población de jóvenes, pueden abarcarlos en su seno, dado que tienen como población objetivo a todas aquellas personas en situación de vulnerabilidad sin ingresos formales en el grupo familiar. Y, según versa en las fuentes del Ministerio de Desarrollo Social (MDs), «El Programa de Ingreso Social con Trabajo» se encuentra orientado a la generación de trabajo genuino y está destinado a aquellos sectores que, a pesar del importante proceso de crecimiento económico experimentado en nuestro país durante los últimos años y de otras herramientas de política social desplegadas, aún no han logrado incorporarse al mercado de trabajo formal. Estos sectores, que constituyen el «núcleo duro» de la desocupación en la Argentina, son el resultado de un proceso de exclusión que lleva décadas y, por lo tanto, requiere de la intervención decidida y sostenida del Estado para revertir las desigualdades generadas durante años» ${ }^{1}$ (MDs: 3 ).

En esta línea, el primer objetivo del Programa es la generación de empleo y la ejecución de trabajos en beneficio de la comunidad, con el objeto de llegar a los sectores más postergados, dándole herramientas para lograr su inserción, a través del trabajo en cooperativas con capacitación. Los participantes de los movimientos sociales, entre ellos los jóvenes, son una porción de sus «beneficiarios», es decir, devinieron en trabajadores «cooperativistas».

A raíz de lo expuesto, debatiremos la influencia de los programas sociales (en particular el Programa de Ingreso Social con Trabajo, conocido como el Programa Argentina Trabaja que, en adelante, denominaremos PAT) en la situación de los jóvenes de sectores urbanos populares, abordando la compleja relación entre los emprendimientos cooperativos, las políticas y las estrategias de los jóvenes participantes en una experiencia territorial dada, en el marco de un Movimiento Social (en adelante ms). Los jóvenes de esta experiencia pueden considerarse originalmente como un subgrupo dentro de los que no estudian y son desocupados -aunque, en la actualidad, ya accedieron al programa referido-.

Para ello, expondremos un esquema que exprese la situación de las intervenciones destinadas a la población joven y, en un marco más general,

1 http://www.desarrollosocial.gob.ar/Uploads/i1/ArgentinaTrabaja/4.\%20Distribuidor\%20 Ingreso\%20Social\%20con\%20Trabajo.\%20Provincias.pdf 
las políticas sociales que ha adoptado el gobierno para atender la situación de los sectores más vulnerables respecto al mercado de trabajo.

Luego presentaremos el Movimiento de Trabajadores Desocupados de Lanús (MTD), actualmente parte del Frente Popular Darío Santillán (en adelante FPDS), que es el sujeto estudiado y base empírica de la investigación. Allí, analizaremos los relatos de los jóvenes «cooperativistas».Y, finalmente, concluiremos proponiendo reflexiones sobre el análisis realizado.

Trabajamos a partir de un enfoque cualitativo. Esta adopción se corresponde con un modo de profundizar en las perspectivas subjetivas de los actores sobre sus experiencias. La consigna orientadora ha sido analizar las trayectorias y las prácticas sociales, económicas y políticas del grupo de cooperativistas nucleados en microemprendimientos productivos (en adelante productivos). De este modo, nuestra unidad analítica refiere a las dinámicas productivas -individuales y colectivas-.

En el estudio, se aplicaron entrevistas individuales semiestructuradas, siendo nuestro universo la totalidad de los trabajadores de los seis productivos que funcionan en este ms: bloquera $^{2}$, panificadora, obra, herrería, serigrafía y carpintería. La labor de campo fue realizada en el segundo semestre de 2012, obteniéndose un total de 26 entrevistas a mujeres y varones, más 6 entrevistas a un informante (referente clave de cada productivo). Resta decir que, dada la temática de este texto, para su elaboración se hizo foco en las 10 entrevistas a mujeres y varones de 18 a 30 años de edad ${ }^{3}$.

\section{LO QUE ABUNDA Y LO QUE FALTA: POLÍTICAS PÚBLICAS, PLANES Y PROYECTOS}

Los estudios académicos sobre la situación de los jóvenes contemporáneos van en notable incremento desde mitades del siglo anterior. El interés sobre este campo ha marchado en paralelo a las transformaciones de distinta índole social, productiva, económica y cultural de nuestras sociedades. Las investigaciones realizadas han retomado con creces las teorías sociales referidas a las mutaciones dadas en las instituciones y en las

2 Bloquera es la denominación de uno de los productivos que realiza bloques de cemento que se utilizan como materiales para la construcción de viviendas.

3 La reconstrucción se basa en los datos suministrados por los informantes del propio ms. Se desestimaron solo tres cooperativistas jóvenes que mostraron reticencias para llevar a cabo la entrevista. 
relaciones sociales, sobre todo aquellas vinculadas a las reestructuraciones del mercado laboral.

Los aportes en relación con la crisis, con el resquebrajamiento de la sociedad salarial y con los soportes institucionales de su andamiaje fueron un motor para el lanzamiento de propuestas teóricas que renovaron la tensión entre integración-desafiliación social, como conceptos claves en la teoría sociológica. Las propuestas más extendidas hicieron eje en las mutaciones de la cuestión social y la vulnerabilidad socio laboral (Castel, 1995).

La vulnerabilidad se considera como un proceso social basado en la acumulación de situaciones de deterioro que acaban en la desafiliación social, es decir, este es el resultante de una dinámica que se expresa en múltiples condiciones que promueven que parte de los miembros de la sociedad se encuentren al margen de las instituciones sociales, y sus efectos constituyen una tensión latente.

En nuestros días, la cuestión juvenil es un eje sobre el cual el epicentro del debate gira en torno a las complejidades de las problemáticas laborales, sus efectos y las respuestas entre los jóvenes contemporáneos. Se advierte un nuevo paradigma de inserción laboral de carácter precario donde las representaciones en torno al trabajo y las estrategias juveniles muestran signos de cambio (Pérez Islas y Arteaga, 2001; Weller, 2004).

En este marco, los sistemas de políticas públicas, tanto en contenido como en sus propuestas, suelen retomar conceptos como la vulnerabilidad socio laboral. Históricamente, la mayor parte de los programas sociales y acciones públicas se presentaron como modos de atención a la pobreza y este acabó siendo su eje central. Actualmente, el combate al desempleo y la precariedad laboral cobran también su lugar.

En Argentina, junto con la expansión del desempleo y la profunda crisis, la red de políticas sociales se fue expandiendo rápidamente como un intento de responder a la situación de los sectores en condiciones más extremas y un modo de atender las acciones de protesta como formas de expresión del conflicto social.

Paralelamente, desde entonces cobraron impulso los estudios académicos en el campo de las transformaciones estatales, sobre los virajes del esquema de las estrategias de intervención pública, profundizando en sus alineaciones políticas, alcances, y efectos. Existe un acervo de materiales que debaten sobre el carácter de los cambios sucedidos en diferentes períodos político-gubernamentales. 
Dos ejes sustantivos de consenso y discusión han sido, por un lado, el ligado a las transformaciones iniciadas durante la década de los 90, que se expresaron en la mutación y el progresivo desmantelamiento de un sistema de políticas públicas caracterizado por un perfil «universalista», y su pasaje hacia otro, donde primó la fragmentación y la dispersión de programas sociales con un peso enfático en la adopción de una estrategia focalizada, señalado, entre otros, por Andrenacci (2002). Otro eje más reciente tiene que ver con el perfil de las intervenciones lanzadas a partir del 2003. En algunos estudios, se trata de un esquema de apertura hacia nuevas formas de generar programas menos asistencialistas, alternativos a los antecesores, mientras que otros advierten sobre la continuidad de las contrariedades en ambos períodos (Golbert, Roca y Lanari, 2012).

Ahora bien, históricamente en Argentina, el campo de lo joven se ha caracterizado por un desarrollo institucional débil y discontinuo, expresado, entre otros, en la escasez de políticas específicas de juventud. Las existentes se tratan más bien de múltiples acciones destinadas a los jóvenes que carecen de una direccionalidad común y un eje articulador.

En definitiva, lo que se discute apela a cuestiones de mayor alcance y hondura, dado que el debate de fondo es sobre el lugar de lo joven en el esquema de la política estatal. Dilemas que, lejos de ser exclusivos de nuestro territorio, están presentes con distinta intensidad y forma en otros países de América Latina (Balardini, Dávila, Paciello y De freitas, 2005).

Ligado a la escasa institucionalidad que detenta el campo, no se visibiliza con clara certeza cuáles son los actores políticos que deberían concentrar la planificación coordinada de este en el esquema de las políticas públicas.

Los expertos entienden la necesidad de diseñar políticas de juventud, procurando lograr una orientación integral en base a una planificación con metas, objetivos y evaluaciones. Las propuestas de intervención apuntan a atender cuestiones como: la finalización del ciclo educativo, la capacitación en oficios e, incluso, el acceso a trabajos decentes en estrecho vínculo con proyectos educativos; en menor medida, aparecen alternativas como generar propuestas colectivas de trabajo (Borzese, Bottinelli y Luro, 2009).

Por otra parte, son muy pocos los estudios que retomaron experiencias vinculadas con poblaciones jóvenes, incluidas como destinatarias en el marco de programas sociales. (Svampa, 2005; Hudson, 2011; Otero, 2010). Son menos aun los estudios académicos que han abordado el componente juvenil y retomado el PAT o programas con similares características (Alsina y Otero, 2013). 
En esta última línea de estudios, a pesar de los diferentes enfoques hay consenso en que las experiencias que transitan se marcan en las perspectivas y comportamientos de los jóvenes. Además, enfatizan en los hitos de transformación dados en las trayectorias advirtiendo la complejidad de las posiciones subjetivas, ya que estos tránsitos y sus significaciones pueden variar notablemente entre los protagonistas. En forma tangencial, señalan obstáculos notorios en la implementación de los programas sociales, límites en sus alcances, transitoriedad y poca amplitud de propuestas.

\section{EJES DE LA POLÍTICA SOCIAL EN EL GOBIERNO ACTUAL}

La relación de los movimientos con el Estado está vertebrada por las disputas en el escenario político-nacional y en el sistema de políticas públicas. Esta relación es sensible a las variaciones en el poder político, así como a las intervenciones de política píblica. Por lo cual, la vinculación entre movimiento y Estado nunca está ni estuvo exenta de las contrariedades abiertas entre la gestión gubernamental y la beligerancia de la protesta.

Por otra parte, la institucionalización de los planes sociales en el cotidiano de los ms demandó cierta logística entre los militantes respecto al manejo de la burocracia estatal. En paralelo, el andamiaje de las políticas mediatizó la relación de los ms con la población subsidiaria e intervino en el desarrollo de la acción colectiva.

El carácter de esta convivencia entre Estado y movimientos sociales es un hecho desde la crisis del 90. A partir de entonces, se impulsaron diferentes intentonas para atender la situación del desempleo. Entre otras, asistimos a la puesta en marcha de programas que fomentaron la ejecución de planes sociales a través de la gestión de onGs; estrategias con pretensiones de universalidad que implicaron una extensión asombrosa de la red asistencial hasta nuestros días, donde la prioridad es la creación/refuerzo del trabajo en cooperativas.

Ahora bien, la asunción del gobierno peronista de Néstor Kirchner (2003-2007) y de Cristina Kirchner (2007 a la fecha) significará la reivindicación de la estabilidad político institucional y el ingreso a un período de relativo crecimiento económico, con una disminución en las cifras de desempleo. En este marco, se pondrán en juego nuevas estrategias que re- 
definirán el escenario político, con un consecuente reposicionamiento de los actores políticos y de los modos de gestionar la cuestión social ${ }^{4}$.

En el campo social, se promoverá una política de pacificación, negociación e integración de los ms al Estado, que desestimará la represión de las protestas populares. A su vez, pasado el período de alta conflictividad social, los movimientos de desocupados perderían la efervescencia inicial. Junto con ello, se iría haciendo aun más difusa la articulación entre los sectores medios y populares más afectados por la crisis. Así las cosas, las direcciones kirchneristas plantearon dilemas a los ms, lo que acabó originando segmentaciones entre aquellos cercanos o confrontados al oficialismo.

En el último período, las respuestas estatales orientadas al desempleo y a los ms se han inclinado a fomentar propuestas lanzadas como promotoras activas de empleo que, si bien no todas son dirigidas específicamente a la población de jóvenes, los abarcan.

La variante se mostró con el lanzamiento del Plan Manos a la Obra (Resolución 1375/MDs/2004), y con el PAT (Resolución 3182/MDs/2009). Ambos estarán apoyados en la delegación de la generación de empleo a los colectivos de trabajadores conformados en cooperativas. Es en este viraje donde el Programa Argentina Trabaja aparece como un caballito de batalla para promover un tipo de articulación integradora.

\section{EL PROGRAMA DE INGRESO SOCIAL CON TRABAJO. ARGENTINA TRABAJA}

El PAT es una iniciativa en marcha desde el Ministerio de Desarrollo Social de la Nación. Está destinado a personas en situación de vulnerabilidad, sin ingresos formales en el grupo familiar, sin prestaciones de pensiones o jubilaciones nacionales ni otros planes sociales, a excepción del Plan Nacional de Seguridad Alimentaria. Sus objetivos son la creación de puestos de trabajo, la capacitación y la promoción de la organización cooperativa. Este programa entiende al cooperativismo como una herramienta eficaz para favorecer la creación de empleo. La finalidad es crear nuevos puestos

4 El dispositivo que orienta el rumbo del sistema de la política pública será el programa Asignación Universal por hijo (Decreto 1602/09 del Poder Ejecutivo Nacional). Es un seguro social para personas desocupadas que trabajan en el mercado informal o que ganan menos del salario mínimo comprendiendo un beneficio por hijos menores de18 años de edad. 
de trabajo a través del fortalecimiento y constitución de cooperativas en el marco de la economía social.

Concretamente, este programa propone el fortalecimiento y la creación de cooperativas de trabajo, a fin de que estas realicen obras públicas vinculadas con labores de baja y mediana complejidad, para el mejoramiento de la infraestructura y el hábitat barrial de las localidades vulnerables. En pocas palabras, se proponen trabajos (como limpieza de plazas, ampliación de espacios comunitarios, etc.), ${ }^{5}$ para mejorar la calidad de vida en los barrios.

El espíritu del programa no solo es la empleabilidad, sino fundamentalmente la capacitación en oficios que implicaría mejorar las posibilidades de acceder a un empleo, es decir, el fin último es la inclusión al mercado laboral.

Los beneficiarios se incorporan al ámbito de trabajo en cooperativas, bajo la figura de efectores sociales. Reciben un ingreso por jornadas semanales de trabajo 40hs. incluyendo capacitación, y teniendo acceso al Monotributo Social. ${ }^{6}$

El Monotributo Social es un régimen tributario creado con el objeto de facilitar y promover la incorporación a la economía formal de aquellas personas en situación de vulnerabilidad social a partir del reconocimiento de sus actividades y de su inclusión como contribuyentes, trabajadores autónomos. De esta manera, están en condiciones de emitir facturas, ser proveedores del Estado por contratación directa, acceder a las prestaciones de las obras sociales del Sistema Nacional de Salud e ingresar al Sistema Previsional (jubilación).

Durante el 2012, el ingreso era de ARG \$1200 por jornada laboral y capacitación, pudiendo percibir un plus por productividad de ARG \$300 y por presentismo de ARG \$250, cuando el salario mínimo vital y móvil era de ARG \$2670. Desde el punto de vista de la protección social, los aportes que corresponden a su condición de monotributista social son subsidiados por

5 Según versa en la página del programa, en éste se promueven actividades como: a) Infraestructura urbana local, como pavimentación de veredas, obras de acceso para personas con discapacidad; b) Infraestructura comunitaria, mediante la ampliación de centros comunitarios; c) Mejoramiento de espacios verdes; d) Mejoramiento habitacional e) Producción comunitaria. La orientación predominante es la ejecución de obras públicas locales. No obstante, incluyen posibilidades acordes con las demandas locales sujetas a la aprobación de los entes y organismos del programa.

6 Véase Argentina Trabaja. Programa Ingreso Social con Trabajo, Guía Informativa. En línea http://mdsn.fvcit.com/Uploads/i1/ArgentinaTrabaja/4.\%20Gu\%C3\%ADa\%20informativa.pdf 
el MDs (Resolución 49.697/10). El ingreso mensual de los cooperativistas se recibe en forma individual a través de una tarjeta bancaria.

La estructura de funcionamiento del Programa se inicia con la convocatoria realizada por los gobiernos locales y la confección de listados de potenciales inscriptos. Después de un proceso de evaluación de los postulantes (basado en una visita domiciliaria y en la aplicación de una encuesta socioeconómica) y a partir de la propuesta de generación de oportunidades laborales por parte de los entes ejecutores, según la situación territorial y el alcance del accionar de la entidad, se establece una nómina de cooperativas que podrán incluirse y deberán inscribirse en el Instituto Nacional de Asociativismo y Economía Social (INAEs) y en el Registro Nacional de Efectores de Desarrollo Local y Economía Social del MDs. ${ }^{7}$

A partir de esa instancia, se suscribe un convenio de cooperación entre el Municipio y el MDs donde se detallan las distintas obras que realizarán y los montos asignados, estableciéndose que la suma correspondiente a mano de obra, capacitación y adelanto de excedentes que es transferida directamente a los asociados de las cooperativas en su cuenta bancaria.

Las obras son tipificadas como "módulos constructivos» y su financiamiento está a cargo del MDs, quien transfiere los fondos necesarios para su concreción al Municipio (u ente ejecutor) bajo la forma de un subsidio institucional.

Siguiendo los datos disponibles, afirman que para el año 2010, a nivel nacional, el monto total de la ejecución del PAT fue de ARG \$3.621 millones sobre un presupuesto original de ARG \$1.500 millones. En 2011 el presupuesto aprobado ascendía al ARG $\$ 3.787$ millones y cerca de un $70 \%$ estaba destinado a la provincia de Buenos Aires (Fernández, 2012: 26). ${ }^{8}$

Dicho programa es uno de los más importantes en términos de recursos y logística y uno de los de mayor alcance en el territorio de la provincia de Buenos Aires. De acuerdo con informes recientes, la cantidad de personas incorporadas al PAT para el 2010 era de 157.089 y, de este total, 137.291 residían en Buenos Aires. Sobre el total de la población incorporada, el grupo etario de 18 a 24 años alcanzaba el 34\%, y la franja de 25 a 29 años, el 15\%. De modo que ambos grupos concentran alrededor del 50\% de los cooperativistas (Fernández, 2012).

7 Los criterios de elegibilidad de los postulantes se verifican cruzando informaciones provenientes de la base de datos tributaria y social del Sistema de Identificación Nacional Tributario y Social y de la Administración Federal de Ingresos Públicos.

8 El Ministerio de Economía y Finanzas Públicas asigna las partidas presupuestarias (Decreto 1067/2009). 
La implementación es planificada por el Poder Ejecutivo Nacional y por sus pares provinciales y municipales. Sin embargo, las tensiones verificadas en la gestión del programa a nivel provincial o municipal son señaladas en diversos estudios y, frecuentemente, ha sido una problemática indicada por los militantes del movimiento bajo análisis.

Por otra parte, el programa no cuenta con reglamentos operativos que definan específicamente el procedimiento de implementación. Los gobiernos subnacionales ofician como entes ejecutores, lo cual los hace permeables a las divergencias territoriales preexistentes y a las históricas formas políticas de desencuentro entre distintos actores políticos (Fernández, 2012).

Pero lo cierto es que el PAT despierta más controversias. Entre otras, pese a que en las normativas aspire a alcanzar fuentes laborales dignas y cooperativas sustentables, los montos mensuales son concebidos como un ingreso social, y el estado apela a los aportes previsionales mediante el monotributo social. El sistema de salud no acompaña totalmente la implementación, y la asistencia sanitaria es un punto suspensivo. Además, la capacitación y las alternativas de educación que promueve son limitadas (Alsina y Otero, 2013).

Sin embargo, la interpelación más aguda es con relación a su misma orientación que, siguiendo a Lo Vuolo, lejos de constituirse como una alternativa de política social, continúa siendo «...un modo estático de regulación de la cuestión social», esta vez, bajo la gestión del empleo forzado, que establece una relación asalariada entre los beneficiarios y el Estado, que fija las reglas del contrato laboral. De modo que, en la práctica, cambian «la dominación que ejerce el poder del capital sobre el trabajo en el mercado, por una dominación ejercida por el poder político» (Lo Vuolo, 2010:19).

La renovada institucionalidad viene a dar cuenta del papel amortiguador que cumple el Estado, ya no entendido solo para transformar y procesar las diferencias sociales, sino para suplir los lugares donde el mercado de empleo se retira y este aparece como mercado de consumo.

Así las cosas, el intervencionismo público prueba un salto cualitativo, apoyado en la delegación de la generación de trabajo a los colectivos de trabajadores conformados en cooperativas, y esta avanzada va a redefinir un mapa territorial con notorias diferencias en lo que hace a las llegadas a los sectores poblacionales más vulnerables.

La pretendida prioridad que el PAT otorga a las experiencias de trabajo colectivo se enfrenta con múltiples obstáculos y restricciones en la marcha. Algunos de los obstáculos son las malas condiciones infraestructurales de los espacios para la cooperativa (falta de luz, agua, etc.) o, incluso, la falta de 
espacios para las tareas administrativas; dificultades técnicas y organizativas que hacen difícil la gestión de las cooperativas; problemas relacionados con la difusión y con las posibilidades de comercialización de las producciones o servicios; bajos recursos de materiales para la ampliación de su desarrollo como cooperativa, etc. Otro obstáculo es sostener la demanda de sus servicios o producciones ante la competencia que deben enfrentar sus productos en el mercado, lo cual hace dudosa su sustentabilidad en el largo plazo y advierte sobre la posibilidad de una continuidad dependiente del Estado.

Para la vertiente de movimientos autonomistas como el caso bajo análisis, el refuerzo de los proyectos de autogestión se anuda con los postulados y con la estructura organizacional del trabajo territorial. Pero, en paralelo, carga con notorias problemáticas neurálgicas que transcienden las construcciones colectivas y el esfuerzo de voluntades. Por ejemplo: los entrecruces intra e intergeneracionales. Es en estos intersticios donde el desempleo es un foco de interrogantes sobre los jóvenes urbanos populares.

\section{LA EXPERIENCIA: JÓVENES EN EL FRENTE POPULAR DARÍO SANTILLÁN}

Perfil del FPDs ${ }^{9}$

El movimiento bajo análisis se asienta en un primer cordón industrial al sur de la provincia de Buenos Aires, más precisamente en una localidad llamada Lanús. Este es un territorio que experimentó un temprano y dinámico proceso de urbanización y presenta una marcada heterogeneidad en su estructura social, conformada por clases medias y sectores obreros.

El movimiento FPDs surgía a fines de la década del noventa (1998) en los barrios más pobres de la zona, afectados por un proceso progresivo de desindustrialización durante un período de crisis económica, política e institucional que comenzó en los 70 y se profundizó en los 90 . Su expresión máxima fue el feroz deterioro laboral y un consecuente avance de la pobreza estructural, exclusión y marginalidad social.

Si bien es una zona histórica y estadísticamente de emergencia prioritaria de intervención estatal, a la par de la crisis, se conformó un territorio

9 Cabe aclarar que desde su fundación hasta el 2004, este MS llevaba el nombre de Movimiento de Trabajadores Desocupados de Lanús (мтD), es por ello que los testimonios de nuestros entrevistados suelen mencionar indistintamente MTD o FPDS. 
cada vez más atravesado y sostenido por la red de políticas públicas. Esta dinámica convergió en un proceso de organización del vecindario en reuniones barriales llamadas «comisiones de desocupados».Allí, confluyeron vecinos sin experiencias previas de participación y ex militantes políticos de movimientos de extracción izquierdista. En su mayoría, los recorridos laborales de ambos grupos se circunscribieron a experiencias inestables e inserciones precarias al mercado de trabajo. Las incipientes comisiones sentarían las bases para la construcción de un movimiento social de composición heterogénea, que fue nucleando, en su mayoría, a mujeres y jóvenes de la zona.

El perfil de este ms presenta una serie de características notorias: a) promueve una clara línea de participación horizontal y de construcción política, montada sobre el trabajo territorial; b) se posiciona en la corriente de movimientos de matriz autónoma, es decir, fuera de registros partidarios, sindicales e institucionales, y c) apela a la acción directa (cortes de ruta y piquetes), como modo de manifestación de la protesta social.

Desde sus orígenes, postula como objetivos motores: trabajo, dignidad y cambio, tanto del sistema capitalista como de los modos de relación social hegemónicos. Siguiendo esta orientación, enfatiza en la creación de grupos de trabajo productivos-comunitarios. La apuesta está guiada por dos lógicas centrales: la autogestión y la propiedad colectiva.Ambas se corresponden con el ejercicio de la propia capacidad -individual y colectiva- para gestionar recursos, administrarlos y producir en beneficio de los intereses del grupo, sin subordinaciones institucionales externas; es decir, con miras a la autosustentación y estableciendo la propiedad colectiva de las herramientas, medios de producción y usufructo.

Las tensiones entre los subsidios estatales y la prédica de la autonomía resultan ejes controversiales en la existencia de los movimientos de desocupados de matriz autónoma. La temática tiñe las disputas políticas entabladas y, es un eje abordado en el campo de las ciencias sociales (Adamosky, 2010).

Desde su génesis hasta la fecha, la institucionalización de los distintos programas sociales (de empleo, alimentos, salud, etc.) es un soporte básico para las acciones del FPDs; que además, por su gran enfrentamiento y capacidad de negociación con el Estado, logró una gestión relativamente autónoma de dichos programas.

Una particularidad del FPDs es que objetó la principal línea de proyectos propuestos por el gobierno nacional bajo el Programa Argentina Trabaja, cuyo eje prioritario -como hemos mencionado en apartados anteriores- se 
encuentra en la rama de las obras públicas. Por el contrario, este movimiento luchó contra el Estado para fortalecer los microemprendimientos que ya estaban funcionando en su interior e incluyó un nuevo grupo de «Obra» (que ejecuta construcciones como: rampas de acceso para personas con discapacidad, ampliación de comedores comunitarios, etc.). Todos estos grupos conformaron una cooperativa de trabajo inscrita en el INAES y sus trabajadores están incorporados al PAT.

Puede decirse que este ms ha logrado cierta independencia en la organización de sus proyectos productivos y en el manejo de los cooperativistas que pretende incorporar, por lo cual, la distribución de los cupos surge a partir de los criterios que establecen hacia el interior de la acción colectiva. En este sentido, el grado de compromiso, la disponibilidad de los compañeros y la antigüedad como activista, operan como criterios informales en los que se basa la deliberación respecto a su adjudicación. Claro está que después tiene que ser aprobado oficialmente por los organismos ejecutores del programa.

Los productivos del FPDs tienen una génesis ligada a la necesidad de dar respuestas materiales a las problemáticas barriales y, en su mayoría, surgen en el momento de expansión extrema de la desocupación. Hasta hoy, promueven una forma de producción cuasi artesanal de muy pequeña escala, orientada a la mercantilización de sus productos. Actualmente, están sustentados por los recursos de la intervención pública; y algunos de tales proyectos obtuvieron, a lo largo de su desarrollo, subvenciones en maquinarias o herramientas en forma irregular y eventual.

A pesar de ser experiencias originadas hace más de una década, las propuestas productivas parecen corresponderse más con una economía de supervivencia que con el desarrollo de una red de economía social próspera.

\section{LA PALABRA DE LOS JÓVENES ${ }^{10}$}

\section{Caracterización del grupo}

Nuestros entrevistados promedian los 27 años de edad, y sus trayectorias sociales, educativas y ocupacionales presentan rasgos transversales.

10 A lo largo de los próximos apartados se apeló a la utilización de nombres o sobrenombres ficticios, con el objeto de mantener el anonimato y preservar la identidad de los entrevistados. 
Entre ellos, que habitan en el barrio y que sus recorridos laborales se circunscribieron a experiencias inestables o precarias en tareas de muy baja calificación en el sector servicios. Todos concluyeron el nivel primario, aunque pocos obtuvieron el título secundario y apenas un par retomaron sus estudios.

Los jóvenes llevan entre 4 meses y 13 años como militantes y, para el conjunto, el ms mediatizó su incorporación como cooperativistas. Desempeñan sus actividades laborales en los núcleos productivos que cuentan con entre 3 a 10 trabajadores (mujeres y varones de distintas edades) que, como aclaráramos, manejan una producción de baja escala, vinculados a trabajos cuasi manuales. Se trata de actividades en serigrafía, carpintería, herrería, obra, panificación y armado de bloques de cemento.

Los relatos: intersecciones entre trabajo y planes

De los discursos producidos por los jóvenes a lo largo de las entrevistas, parece resultar que perciben con claridad una distancia abismal entre sus pasos previos en el mundo laboral y la experiencia que transitan como cooperativistas. De hecho, a la hora de establecer comparaciones, no dudan en reseñar una serie de cualidades que hacen del espacio de trabajo del hoy un ámbito positivamente valorado. Más que por el desafío de las tareas que se realizan, la valoración se asienta en la ausencia de una rigidez disciplinaria que los someta a su ocupación. Junto a esta suerte de autonomía, se exaltan los lazos afectivos y el compañerismo generado.

Acá nadie te va a estar diciendo ¡dale, andá, hacé esto, hacé lo otro! Vos sabés que tenés la obligación, que lo tenés que cumplir, pero no los tenés encima tuyo las 24 horas, que te estén gritando, que te estén tratando mal. Somos todas encargadas, pero no te van a decir: ¡hacé esto, hacé esto!... (Andrea, mujer, 26 años. Panadería).

[...] como que es más sentimental el tema del MTD, porque ya nos conocemos todos, somos como familia ya... pasamos mayormente el tiempo acá, y si no tenemos para hacer nada, estamos todos ahí adelante... En el otro trabajo no, yo al otro trabajo voy y trabajo. Me hablo, conozco al muchacho que trabaja conmigo, pero es como diferente, porque a veces agarré laburo que no conocía y que era para trabajar... (Marcelo, varón, 21 años. Herrería).

En cierto modo, la reconstrucción de las trayectorias laborales, previas al proceso de inclusión al movimiento social, encuentra puntos símiles entre los varones y las mujeres del grupo, dado que los relatos describen, 
una y otra vez, pasajes por trabajos en condiciones laborales muy precarias y, en su mayoría, por cortos períodos.

En el 2005, estuve en un kiosco trabajando. Ahí trabajaba 12 horas; de las 6 de la tarde a las 6 de la mañana. Qué se yo... atender, acomodar las revistas, la caramelera. Estuve un mes porque había que estar 12 horas, más 2 o 3 horas de viaje y, aparte, yo ya estaba en el Movimiento y yo quería seguir estando en el Movimiento (Leo, varón, 28 años. Bloquera).

Me fui de lo de XXX porque era muy malo el trato con la encargada... te gritaba o te faltaba el respeto muchas veces y era como que yo me lo bancaba por mi hija... a veces yo no podía todo el horario, me levantaba a las 4 de la mañana para entrar a las 6 y era todo el día, no podía hacer eso porque mi hija era chiquita (Andrea, mujer, 26 años. Panadería).

Se reconocen con pocas chances de competir ante posibles empleos y, en cierta medida, parecen reticentes a la opción de retomar las situaciones que marcaron los tramos laborales previos. Las expectativas de reincidir en las ofertas de trabajos disponibles son pocas y exiguas; aunque tampoco se trata de desperdiciar las ocasionales propuestas que aparezcan en el camino, es decir, hacerse de una changa o de trabajos cuasi ligados a la supervivencia. En breves palabras, esta disponibilidad encuentra referencia en «lo que sale»; se trata de ocupaciones eventuales que puedan surgir en el día a día y que, por su misma transitoriedad, no resultan excluyentes de la práctica actual. De modo que echan mano a cierta lógica poco planificada de combinaciones o alternancias entre changas y planes sociales como posibles fuentes de ingreso.

[...] capaz porque me salen changas, ¿̇iste?, y a mí la plata me viene bien como a todos.

¿Y qué tipo de changas?

Y, ponele: hay que cortar un árbol, levantar una pared... changas.

(Chino, varón, 27 años. Herrería).

Sí, me imagino fuera del MTD, pero no sería lo mismo, sería como que recién empezaría a trabajar en el tema de adaptarme. No sé si aguantaría mucho... El Movimiento me dio mucha enseñanza, yo aprendí muchas cosas acá. El tema de sociabilidad con la gente... (Luciano, varón, 27 años. Herrería).

La experiencia actual también es valorada a partir de una historia compartida sobre la lucha popular, que marcó a fuego la emergencia del ms en los períodos más álgidos de beligerancia desde fines de los 90. La necesidad material supone la base estructural de una dinámica de acción colectiva, bajo un formato de protesta social de acción directa, en este caso, los cortes de ruta. La alternancia entre el trabajo y la demanda son parte de un 
estilo propio y ambiguamente definido como una ligazón entre la necesidad y la elección, entre un «laburo» y un «estar».

Pero además, las actividades en las cooperativas refuerzan el sentido de pertenencia al colectivo y, a su vez, las expresiones dan pistas de un claro rechazo al empleo dependiente.

\begin{abstract}
Vengo todos los días acá... Es mi laburo. Aparte lo tomo como una... ya... como una... parte mía, digo, estar en MTD, digo, salir a luchar con los compa... toda la historia que pasamos. No sólo es el laburo lo que me... digo, lo que... te ata acá. Porque si bien estamos todos por una cuestión de necesidad, ¿no?, por eso salimos a pelear todos juntos, pero después... nada, estamos. Por eso, lo que podemos generar entre nosotros, lo que podemos hacer de trabajo y eso... es mucho mejor poder hacerlo entre nosotros, decidir las cosas entre nosotros, que el patrón no se te quede con..., no sé, parte del sueldo, ¿̨no?, como pasa en un montón de casos.Y decimos: Che, mañana vamos a luchar.Y no, no... no trabajamos y lo decidimos entre todos y digo, eso. Eso es lo bueno de poder estar entre los compañeros. Por esa elección también estoy acá (Darío, varón, 27 años. Obra).
\end{abstract}

Ahora bien, la trama de los planes sociales no es una situación innovadora en el territorio y las políticas públicas (salud, alimentos), puede decirse que ha sido una constante en estos barrios urbanos castigados. Para la generación del 80 y del 90, a la cuales pertenece el grupo, la experiencia se corresponde con un escenario de yuxtaposiciones de planes y programas sociales de diverso cuño. Desde los 90, a diferencia de décadas anteriores, se expanden aquellas intervenciones estatales que, entre la asistencia y la contraprestación, atienden los problemas derivados de la falta de trabajo.

Los pasajes por los planes sociales van marcando una dimensión propia en las trayectorias de los jóvenes. Los recorridos que reconstruyen nuestros entrevistados vienen a la par de una larga cadena de sucesivos programas de política social que fechan en las últimas décadas. De hecho, en los relatos van tomando cuerpo una zaga poco diferenciada de planes sociales que admiten períodos de discontinuidad y reingresos. Con frecuencia, pero no unívocamente, los planes aparecen ligados a la historia de su participación con el movimiento social, mostrándolo como mediador de una particular vinculación con el Estado.

Es más, las políticas sociales van a la par de los recorridos de estos jóvenes que encarnan en las trayectorias su rol como participantes. Claro que, el carácter singular de cada historia refleja modos diversos de vinculación entre los beneficiarios, la distribución y la gestión de la política social. 
En el 2000 empecé a cobrar mi primer plan, que era en planes Bonaerense de 150 pesos, que era de provincia, - PEL $^{11}$ y JEFES ${ }^{12}$ eran de Nación-. Después de eso, nos aumentaron a 200 pesos en el 2007-2008, después se me cayó el plan y empecé a cobrar cooperativa hace 2 años de 1200 pesos (Walter, varón, 30 años. Serigrafía).

Ingresé al MTD hace doce años por una hermana. Porque yo estaba embarazada y estaba sin trabajo. Y mi hermana me dijo: vamos que... Yo estaba con un plan, 150 pesos. Y ahí empecé, y vine acá [...] Y después en el MTD ... Yo era como que cobraba Plan, al estar en negro, yo cobraba acá y era como una changuita, ¿entendés? Ponele que era para ayudar más al comedor... (Andrea, mujer, 26 años. Panadería).

En esta trama de historias entre movimientos sociales y Estado, se involucran nuevos mecanismos y pactos de convivencia. La lucha política no se agota en las manifestaciones de protesta social, sino que encuentra una suerte de continuidad en la lucha por los cupos restrictivos de los planes sociales. Es en esta suma de tensiones donde tiene lugar la búsqueda por los accesos. El fragmento del relato expuesto a continuación expresa con claridad que el esfuerzo y la dedicación se reconocen como criterios legítimos y claves en la competencia por su obtención.

Por la participación, por la dedicación que le das. Porque no es que es fácil, al ser muchos, y hay pocos cupos por ingresar, la prioridad es el que participa, el que lucha en los cortes, que tiene participación en los trabajos. Como que le interesaría, mejor dicho, una forma de decir. Que le interesa de verdad (Luciano, varón, 27 años. Herrería).

Hasta aquí, recorriendo los discursos de los entrevistados en las historias de antes y durante su estadía en el FPDs, es notorio que una serie de términos, como la espera, la caída y la suma, cobran espacio en esa ida y vuelta de reiterados pasajes por la política pública. No obstante, para algunos, las experiencias actuales parecieran adquirir un matiz bien diferente tras el reciente PAT que los incorpora en carácter de cooperativistas.

Antes de ingresar al Movimiento, hacía changas semanales de albañilería, electricidad... Eran muy de vez en cuando y así como no seguido. Porque yo iba al colegio, pero después mi novia quedó embarazada y tuve que salir a buscar laburo. Después... mediante mi tía, que es una de las encargadas acá, y un amigo de mi tía, yo ingresé a las cooperativas, ingrese acá a herrería. Cuando se hizo el taller de herrería, ingresé a uno de los talleres de

11 Programa de Emergencia Laboral/Comunitario (P.E.L/C), Ministerio de Trabajo, Empleo y Seguridad Social. Resolución MTEySS N. ${ }^{\circ} 327 / 98$.

12 Programa de Jefes de Hogar, también denominado Derecho Familiar de Inclusión Social: Plan Jefes y Jefas Desocupados, Ministerio de Trabajo, Empleo y Seguridad Social. Resolución N. ${ }^{\circ} 312 / 02$. 
herrería.Yo, antes de entrar acá, no sabía nada de herrería.Ahora soy como uno de los que más... con otro chico... de los que más saben... (Marcelo, varón, 21 años. Herrería).

Las opiniones exponen contrastes y distintos aspectos de la situación individual y colectiva que atraviesan. Por ejemplo, en el caso siguiente, la intervención estatal aparece en cierto modo invisibilizada, como lógica de soporte de las tareas de la acción colectiva que representa este movimiento social. Antes que el atravesamiento de los planes sociales, el énfasis está puesto en la lucha social que guarda correlato con las difíciles, pero existentes, ideas de proyección a futuro.

La verdad que se me hace difícil pensar en un futuro, ¿no? Porque a veces el día a día... para los cambios más pasan años, ¿̨no? Porque más porque no tenemos ayuda y generamos nosotros mismos las cosas que hacemos a pulmón, pero yo me lo sigo imaginando como ahora, ¿no? Digo, donde es que seguimos buscando la vuelta a lo que es trabajo y haciendo nuestras prácticas... de charlar, de maneras de organizarnos, de discusión, digo, potenciar así como son estos dos ejes de lucha sin grandes saltos, ¿no? (Leo, varón, 28 años. Bloquera).

Más allá de la participación militante, la incorporación de trabajadores, es decir, nuevas camadas que logren un ingreso laboral, tiene como contraparte la realidad que encierra el fenómeno persistente del desempleo. Lo cual se manifiesta con contundencia entre la población de los jóvenes de estos barrios pobres del conurbano bonaerense, al sur de la provincia de Buenos Aires. La gente de afuera -afuera del movimiento y de las políticas públicas activas de empleo- muestra una vez más los dislocamientos y las fragmentaciones producidas en el mundo popular, tributarias de las transformaciones en el mundo del trabajo y de sus consecuentes efectos de saldo en la cuestión social.

Sumar más compañeros y, como te diría... para poder dar más trabajo a la gente porque hay mucha desocupación. Hay gente que por ahí no la ves y hay gente que la vemos, y eso me llega, el hacer cosas para que una gente de afuera, que no tenga trabajo, pueda venir a trabajar es una alegría (Chino, varón, 27 años. Herrería).

\section{APUNTES FINALES}

El PaT tiene como intención la inclusión de los sectores más vulnerables de la población a través de la creación y el fortalecimiento de las empresas sociales, mutuales y cooperativas en el marco de la Economía Social. Sus 
objetivos son la creación de puestos de trabajo, la capacitación y la promoción de la organización cooperativa.

En los hechos, los ingresos mensuales que aporta son insuficientes para el sostenimiento de la economía familiar. En los sectores incorporados al programa, no se observan mejoras sustantivas en cuanto a su situación económica y social.

De acuerdo con lo analizado, las políticas públicas no parecen estar revirtiendo totalmente la situación de estos jóvenes, ni alterando sustantivamente su situación económica.Antes bien, sostienen un proceso de degradación en el que se encuentran sumergidos los sectores populares y refuerzan una identidad social de vulnerabilidad.

Las políticas públicas parecen contar con escasos recursos para permitir una mejoría sustantiva de las condiciones de los sectores incorporados, y la transitoriedad de los programas sociales y los pocos apoyos de desarrollo sustentable de la economía social no refuerzan la solidez de esta vía.

En ese sentido, las cooperativas generadas se enfrentan con múltiples obstáculos y restricciones en la marcha. Algunos de los obstáculos son las malas condiciones infraestructurales de los espacios para la cooperativa (falta de luz, agua, etc.) y la falta de espacios para las tareas administrativas; los problemas relacionados con la difusión y con las posibilidades de comercialización de las fabricaciones; o bajos recursos para la ampliación de sus producciones.

Otro obstáculo está relacionado a la competencia que deben enfrentar sus productos en el mercado. Esto hace que sea incierta su sustentabilidad en el largo plazo y advierte sobre la posibilidad de una dependiente continuidad con el Estado y el programa público.

Frente a ello, nos preguntamos si las cooperativas podrán ser una fuente de trabajo genuino y sostenible en el largo plazo, independientes de las fuentes de recursos estatales. Es decir, si las cooperativas lograrán sustentabilidad y autonomía, y si los trabajadores lograrán ingresos sustantivos a largo plazo para el sostenimiento familiar.

No obstante, la experiencia que transitan a través de su integración como cooperativistas en el marco del ms es valorada positivamente por el grupo de jóvenes entrevistados. Esta consideración se asienta sobre todo en los lazos afectivos que se generan entre los compañeros de los espacios de trabajo y, a su vez, las actividades en las cooperativas refuerzan el sentido de pertenencia al colectivo (FPDS). 
Es decir, que la otra cara de la situación es que análogamente las políticas son una condición de posibilidad para nichos alternativos de trabajo colectivo. Desde aquí, el FPDs, como micro contexto sociopolítico y económico, constituye una red de redes sociales, un espacio de socialización y de acción valorado por el grupo de entrevistados.

Entonces, tomando en cuenta lo analizado en la experiencia que retomamos, podemos concluir que la función del pAT es más la de estimular la generación de lazos sociales y vínculos afectivos entre los compañeros de la cooperativa que la de provocar realmente una inclusión sólida y duradera tanto de las cooperativas como de los jóvenes trabajadores que las integran.

\section{BIBLIOGRAFÍA}

Adamosky, E. (2009): «Problemas de la política autónoma: pensando el pasaje de lo social a lo político» en Hoetmer, R. (coordinador). Repensar la política desde América Latina. Cultura, Estado y movimientos sociales, Lima, Programa Democracia y Transformación Global. En línea.http://biblioteca. hegoa.ehu.es/system/ebooks/19555/original/Repensar_la_politica_desde_ America_Latina.pdf?1383559594 [Consultado 17.12.2013].

Alsina, P. y Otero, A. (2013): «Resignificaciones del trabajo según las experiencias políticas en los movimientos de desocupados. Un estudio sobre emprendimientos autogestivos», en Revista da ABET (Brazilian Journal of Labour Studies), Volumen 12, N. ${ }^{\circ}$ 1. Jan/jun 2013. pp. 25-42..

ANDRENACCI, L. (2002): Cuestión social y política social en el Gran Buenos Aires, Buenos Aires, Ediciones al Margen, Universidad Nacional de General Sarmiento.

Balardini, S., Dávila L., Paciello, S. y De Freitas (2005): Políticas Locales de Juventud. Experiencias en el Cono Sur. Friedrich Ebert Stiftung (FEs).

Basualdo, E. (2000): Concentración y Centralización del capital en la Argentina durante la década del noventa, Buenos Aires: Facultad Latinoamericana de Ciencias Sociales/ Universidad Nacional de Quilmes.

Borzese D., Bottinelli, L. y Luro, V.G. (2009): Hacia una ley nacional de juventudes en Argentina. Análisis de experiencias de construcción de leyes de juventud en países de América Latina. Fundación Carolina: Centro de Estudios para América Latina y la Cooperación Internacional (cealci). 
Castel, R. (1995): «De la exclusión como estado a la vulnerabilidad como proceso», en Archipiélago: Cuadernos de crítica de la cultura, $\mathrm{N} .^{\circ} 21$, Madrid.

FERNÁNDEZ, J. P. (2012): La implementación del programa Argentina trabaja en ámbitos Subnacionales. Documento de trabajo 96. Buenos Aires: Centro de Implementación de Políticas Públicas para la Equidad y el Crecimiento (CIPPEC).

Golbert, L., Roca, E. y LANARI, E. (2012): ¿Piso o sistema integrado de Protección social? Una mirada desde la experiencia Argentina, Buenos Aires, Ministerio de Trabajo, Empleo y Seguridad Social (MTEyss). Secretaría de Seguridad Social.

Hudson, J. P. (2011): Acá no, Acá no me manda nadie..., Buenos Aires, Tinta de limón.

Lo Vuolo, R. (2010): «El Programa «Argentina Trabaja» y el modo estático de regulación de la cuestión social del país» en Documento de Trabajo, N. ${ }^{75}$, Buenos Aires, Centro Interdisciplinario para el Estudio de las Políticas Públicas (CIEPP). En línea: http://www.ciepp.org.ar/trabajo.htm [Consultado 18.02.2013].

Ministerio De Desarrollo Social (mDs). Argentina trabaja.Programa Ingreso Social con Trabajo, Guía Informativa. En línea: http://mdsn.fvcit.com/ Uploads/i1/ArgentinaTrabaja/4.\%20Gu\%C3\%ADa\%20informativa.pdf [Consultado 20.09.2013].

Otero, A. (2010): «Jóvenes trabajadores, jóvenes luchadores. Reflexiones sobre experiencias contemporáneas», en Nómadas, Número 32, Abril 2010. Instituto de Estudios Sociales Contemporáneos (IESCO)/ Universidad Central, pp.163/178, Bogotá, Colombia.

Pérez Islas, J. A. y Arteaga, M. (2001): «Los nuevos guerreros del mercado. Trayectorias laborales de jóvenes buscadores de empleo» en Pieck, E. (Coord.), Los jóvenes y el trabajo: la educación frente a la exclusión social (pp. 355-399), México, Fondo de las Naciones Unidas para la Infancia (UNICEF) - Centro Interamericano para el Desarrollo del Conocimiento en la Formación Profesional (CINTERFOR) - Organización Internacional del Trabajo (OIT).

Svampa, M. (2005): La sociedad excluyente: la Argentina bajo el signo del neoliberalismo. Buenos Aires, Aguilar. Altea, Taurus, Alfaguara.

WELLER, J. (comp.) (2004): En búsqueda de la efectividad, eficiencia y equidad. Las políticas del mercado del trabajo y los instrumentos de evaluación, Santiago, Chile, Col. Políticas Sociales, Comisión Económica para América Latina y el Caribe (CEPAL), Lom Ediciones. 